Contract No. and Disclaimer:

This manuscript has been authored by Savannah River Nuclear Solutions, LLC under Contract No. DE-AC09-08SR22470 with the U.S. Department of Energy. The United States Government retains and the publisher, by accepting this article for publication, acknowledges that the United States Government retains a non-exclusive, paid-up, irrevocable, worldwide license to publish or reproduce the published form of this work, or allow others to do so, for United States Government purposes. 


\title{
Tuning Silicon Nanorods for Anodes of Li-Ion Rechargeable Batteries
}

\author{
Ming $\mathrm{Au}^{* 1}$, Brenda Garcia-Diaz ${ }^{1}$, Thad Adams ${ }^{1}$, Yuping $\mathrm{He}^{2}$, Yiping Zhao², Reza Shahbazian Yassar ${ }^{3}$, \\ Hessam Ghassemi $^{3}$
}

\author{
1. Savannah River National Laboratory, Aiken, SC, USA \\ 2. University of Georgia, Athens, GA, USA \\ 3. Michigan Technological University, Houghton, MI, USA
}

\begin{abstract}
Silicon is a promising anode material for Li-ion batteries in regarding of high capacity, low cost and safety, but it suffers poor cycling stability due to the pulverization induced by severe volume expansion/shrinkage (297\%) during lithium insertion/extraction. In our previous investigation on aluminum nanorods anodes, it is found the selection of substrates in which $\mathrm{Al}$ nanorods grown plays the role in prevention of pulverization resulting in the increase of cycling life [1]. Adapting this knowledge, we investigated the Si based nanorods anodes by tuning its composition and element distribution. Our results show that although the Si nanorods demonstrated higher initial anodic capacity of 1500 $\mathrm{mAh} / \mathrm{g}$, it diminished after 50 cycles due to morphology change and pulverization. By codepositing $\mathrm{Cu}$, the $\mathrm{Si}-\mathrm{Cu}$ composite nanorods demonstrated sustainable capacity of 500 $\mathrm{mAh} / \mathrm{g}$ in 100 cycles attributing to its flexible and less brittle nature.
\end{abstract}

\section{Introduction}

Currently, the plug-in hybrid and electric vehicles are leading the migration from of fissile fuel transportation to renewable energy transportation. Developing advanced batteries with high energy densities and low cost is one of several technical barriers of this great migration. A number of metals and metal oxides have been investigated for next generation of high capacity anodes [1-11]. However, the large volume expansion (300-400\%) during metal-Li alloying or oxide-Li conversion causes pulverization of anode materials and results in rapid decrease of high capacity. To insure the electric conductivity and compact cell structure, these powdery metals and metal oxides must be mixed with conductive additives, binders and solvent before being pasted on current

collectors. This electrode fabrication process is complicated and costly. The current density is also limited due to lack of direct contact of active materials and current collectors. Growing aligned nanostructures (i.e., nanorods) of active materials on the electrodes represents one of the solutions for above problem. The interstitial space in aligned nanorods (NRs) may accommodate the volume expansion of the NRs and provide more access sites for $\mathrm{Li}$ ion shuttling that reduces the stress could resulting in longer cycling life. In our previous study, the high capacity of aluminum nanorods is not sustainable during repeatedly charging and discharging due to morphology changing and peeling off from current collectors [1]. Distributing strain and stress gradually along the nanorods may provide a solution for retention of initial high capacity. In this work, we deposited silicon and copper both in with gradient of mixing ratio. The results show that the cyclability of Si-Cu composite nanorods was improved. 


\section{Experimental}

A thin film of aligned silicon nanorods (Si NR) and silicon-copper composite nanorods ( $\mathrm{SiCu} \mathrm{NR}$ ) were grown on the Cu substrate using glancing angle deposition. The details were reported in the previous publication [1]. A glass slide was coated with a homogenous $\mathrm{Cu}$ thin film as the substrate in a sputtering chamber. The morphology and structure of Si and Si-Cu NR were characterized by Scanning Electron Microscope (SEM), Transition Electron Microscope (TEM), Atomic Force Microscope (AFM) and $\mathrm{X}$-ray diffractometer (XRD) respectively. To comparison the mechanical rigidness and flexibility, the individual Si NR and SiCu

NR were separated from thin film deposition and measured their Force-Displacement curves with AFM. A baker cell of Li-ion battery was constructed in VAC glove box filled with argon. The Si NR anode coated slide and a Li foil (Aldrich) were inserted in the cell as the anode and cathode respectively. The $1 \mathrm{M} \mathrm{LiPF}_{6}$ in PC/DMC (Propylene Carbonate and Dimethyl Carbonate) was purchased from Ferro and used as the electrolyte. Princeton Applied Physics' VersaSTAT-3 was used for measurement of electrochemical properties of the new anodes. The galvanic charge-discharge was carried out at $700 \mathrm{~mA} / \mathrm{g}$ from $0.01 \mathrm{~V}$ to $3.00 \mathrm{~V}$. Cyclic voltammetry $(\mathrm{CV})$ was measured at $0.1 \mathrm{mV} / \mathrm{s}$ from $0.01 \mathrm{~V}$ to $3.00 \mathrm{~V}$. To observe the morphology change, the Si NR anodes were taken out of the cell for characterization at different states of virgin, 50\% discharged, 100\% discharged and after 100 discharge-charge cycles.

\section{Results and Discussion}

\section{Materials characterization}

SEM and TEM images show that the average diameter and length of the Si NR and SiCu NR are 30-50 nm and 1.5-2.0 $\mu \mathrm{m}$ respectively (Fig. 1). X-Ray Diffraction (XRD) spectrum indicated that the Si NR are in amorphous state (Fig.2). However, the XRD of $\mathrm{SiCu} \mathrm{NR}$ does show the $\mathrm{Si}$ is in alloying state with the $\mathrm{Cu}$ (Fig.3). The ForceDisplacement curves measured by AFM shows that SiCu NR is more flexible and may less brittle than Si NR (Fig.4).

\section{Cyclic voltammograms of the Si NR and SiCu NR}

The cyclic voltammograms of Li/Si NR and Li/SiCu NR cells are shown in Fig 5. During the charge, the current increases rapidly at $0.75 \mathrm{~V}$ corresponding to lithiation and formation of $\mathrm{Li}_{12} \mathrm{Si}_{7}$ compound. The lowest potential reached was $0.2 \mathrm{~V}$ associated with formation of high $\mathrm{Li}$ compound $\mathrm{Li}_{21} \mathrm{Si}_{5}$. There are several peaks in the first CV cycle of $\mathrm{Si}$ NR that may attribute to the conversion of amorphous Si to crystalline Si-Li alloy in lithiation process. The curve became smooth in the second cycle because of completing of activation process, but the current increase is much smaller than $\mathrm{SiCu}$ NR. It indicates that the electric conductivity of Si NR may not as good as SiCu NR. 


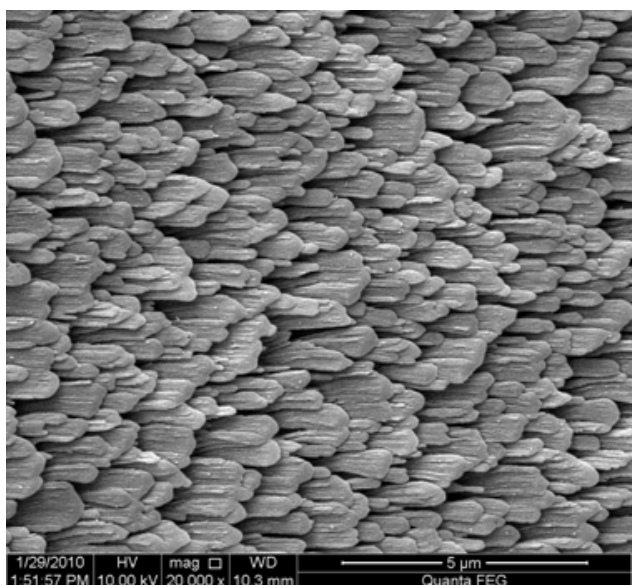

Fig.1 (a) The SEM top view of Si nanorods $(\mathrm{x} 20,000)$

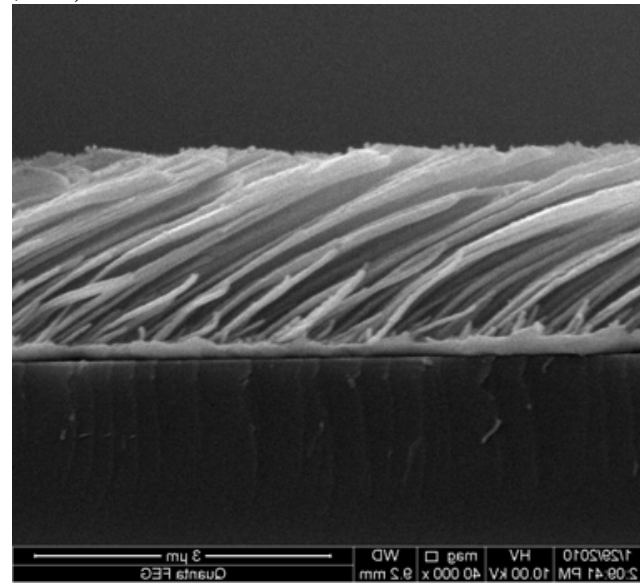

Fig.1 (b) The SEM side view of Si nanorods. The length of $\mathrm{Si}$ is $1.5 \mu \mathrm{m}$. The thickness of $\mathrm{Cu}$ substrate is about $200 \mathrm{~nm}(\mathrm{x} 40,000)$

Fig.1 The SEM and TEM images of virgin Si nanorods

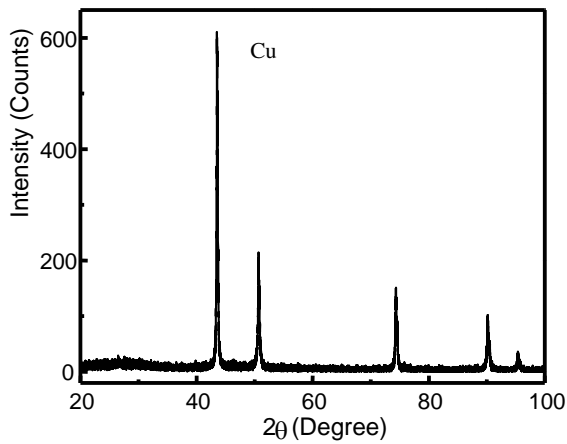

Fig.2 XRD of the aligned Si NRs. The $\mathrm{Si}$ is in amorphous state and undetectable by XRD. All of peaks correspond to $\mathrm{Cu}$ substrate.

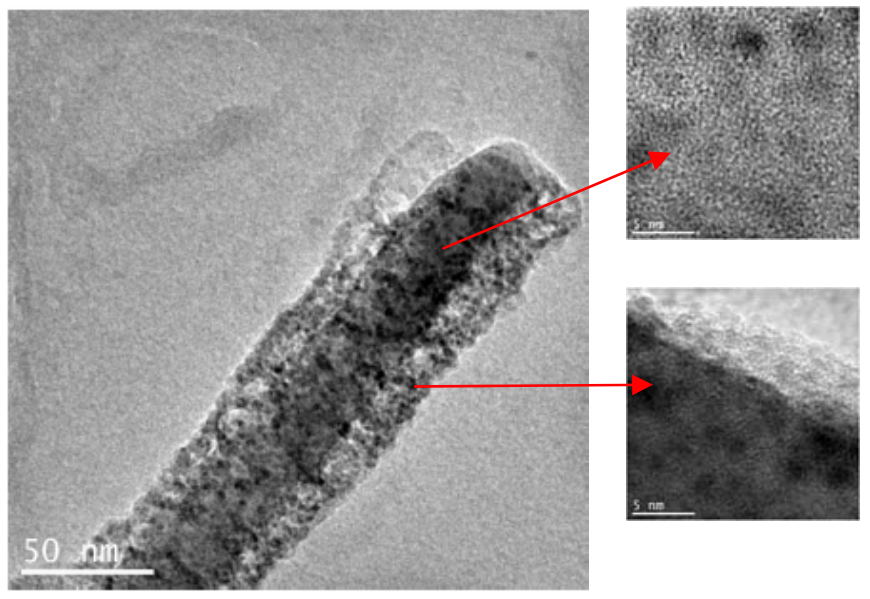

Fig.1(c) TEM image of single Si nanorods. It is in amorphous state. The average diameter and length are $30-50 \mathrm{~nm}$ and 1.5$2 \mu \mathrm{m}$ respectively. Si NR

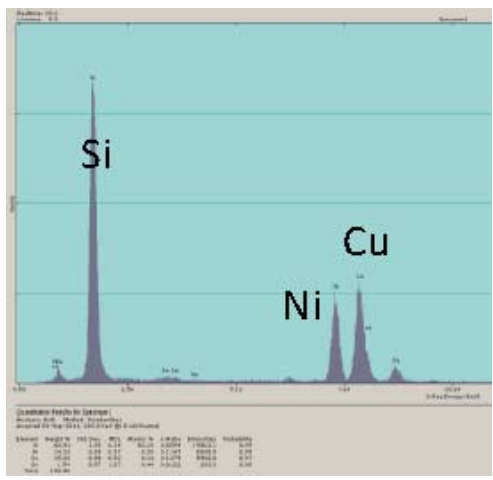

Fig.1 (d) EDS of SiCu NR. Ni comes from TEM grid 


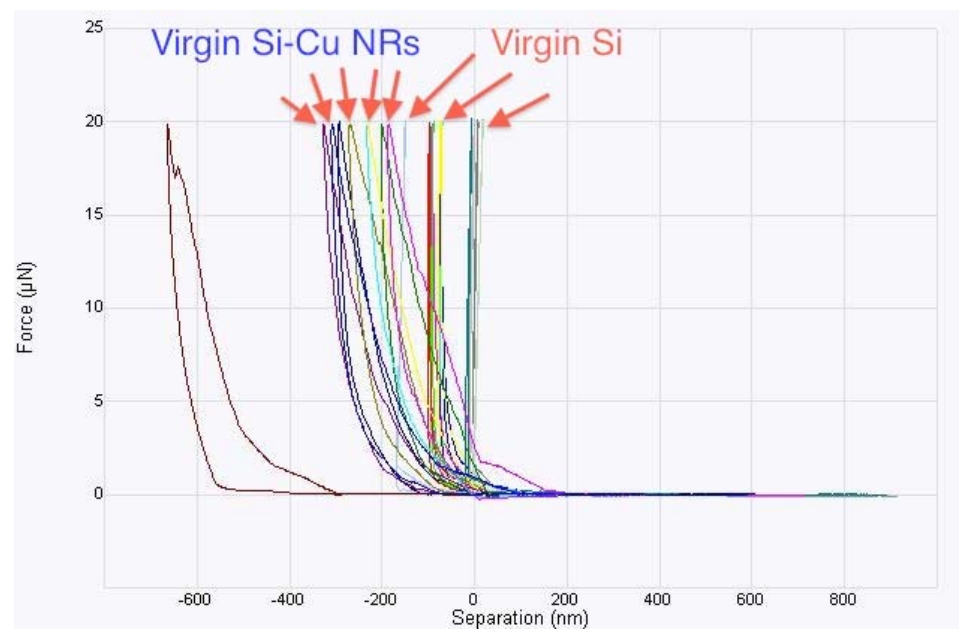

Fig.4 The Force-Displacement curves of Si NR and SiCu NR

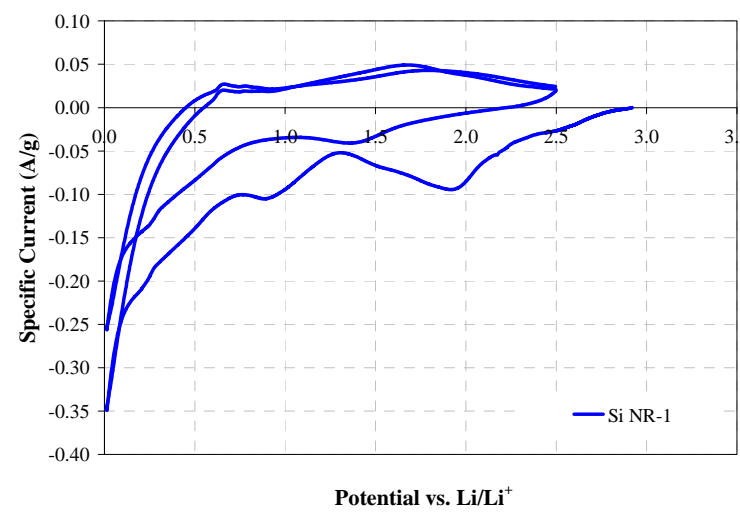

Fig.5(a) CV of Li/Si NR cell (2 cycles)

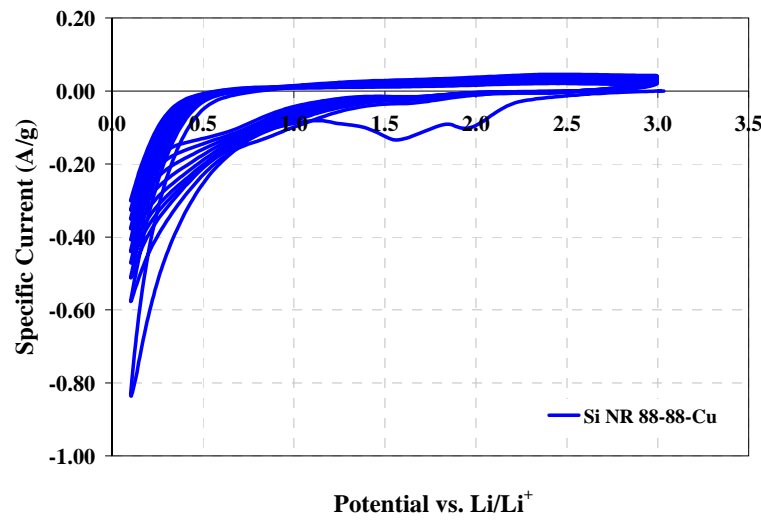

Fig.5(b) CV of Li/SiCu cell (10 cycles)

Fig.5 The cyclic voltammagrams (CV) of Li/Si NR and Li/SiCu cells

\section{The Cyclability and morphology of Si NR and SiCu NR}

The Li/Si NR cell shows the high capacity as $1500 \mathrm{mAh} / \mathrm{g}$ in the first charge (Fig.6). However, the high capacity was quickly diminished in the following 50 cycles (Fig.7). The SEM observation indicates that the nanorods were swollen after first charge and then pulverized as the loose particles during cycling (Fig.8). The Si NR also loses direct electrical contact with the $\mathrm{Cu}$ substrate resulting in diminishing of electrical storage capacity. The TEM images show that the lithiation introduces crystallization of $\mathrm{Li}-\mathrm{Si}$ compounds (new lattice pattern) companioning with the stain and stress (fringes) (Fig.9). After delithiation, the nanorods return to amorphous state with rough surface (Fig.10). 


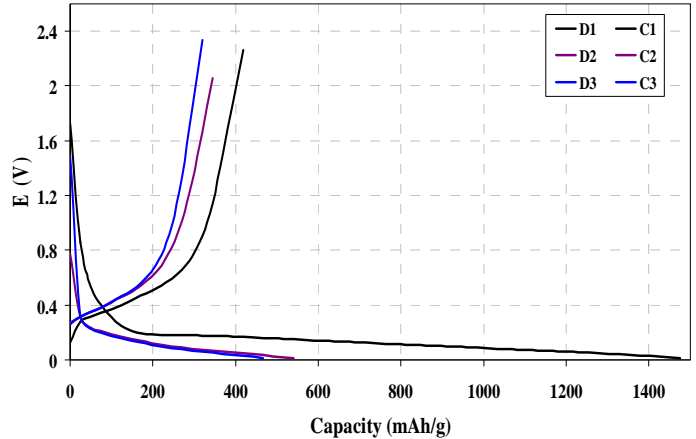

Fig.6 The first three cycles of Li/Si NR cell

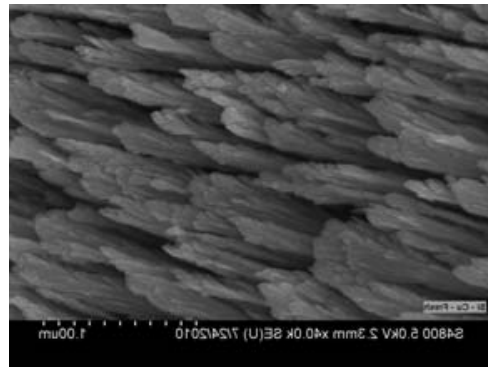

(a) The virgin Si NR

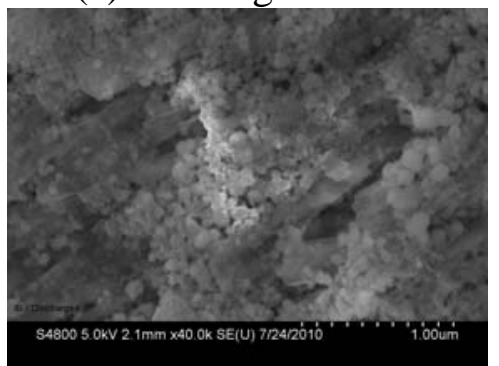

(c) $100 \%$ charged Si NR

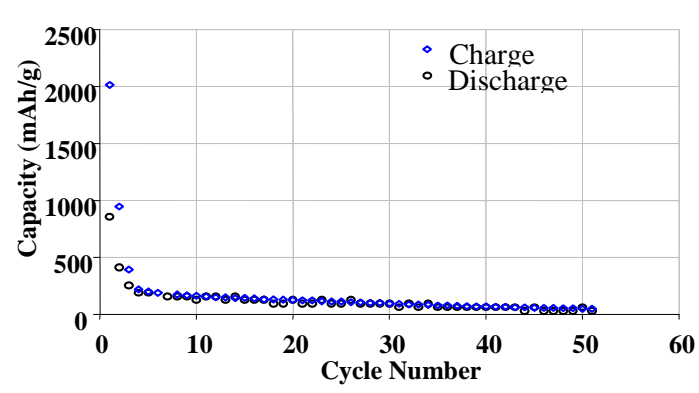

Fig.7 The cyclability of Li/Si NR cell

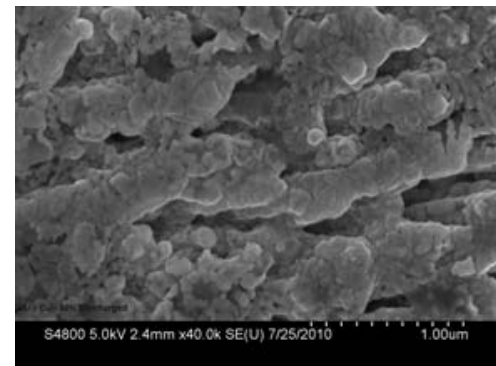

(b) $50 \%$ charged Si NR

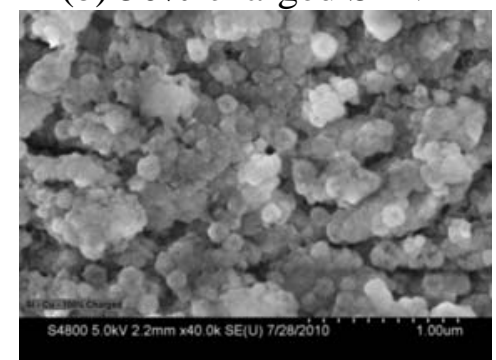

(d) Full charge after 100 cycles

Fig.8 SEM morphology of Si NR

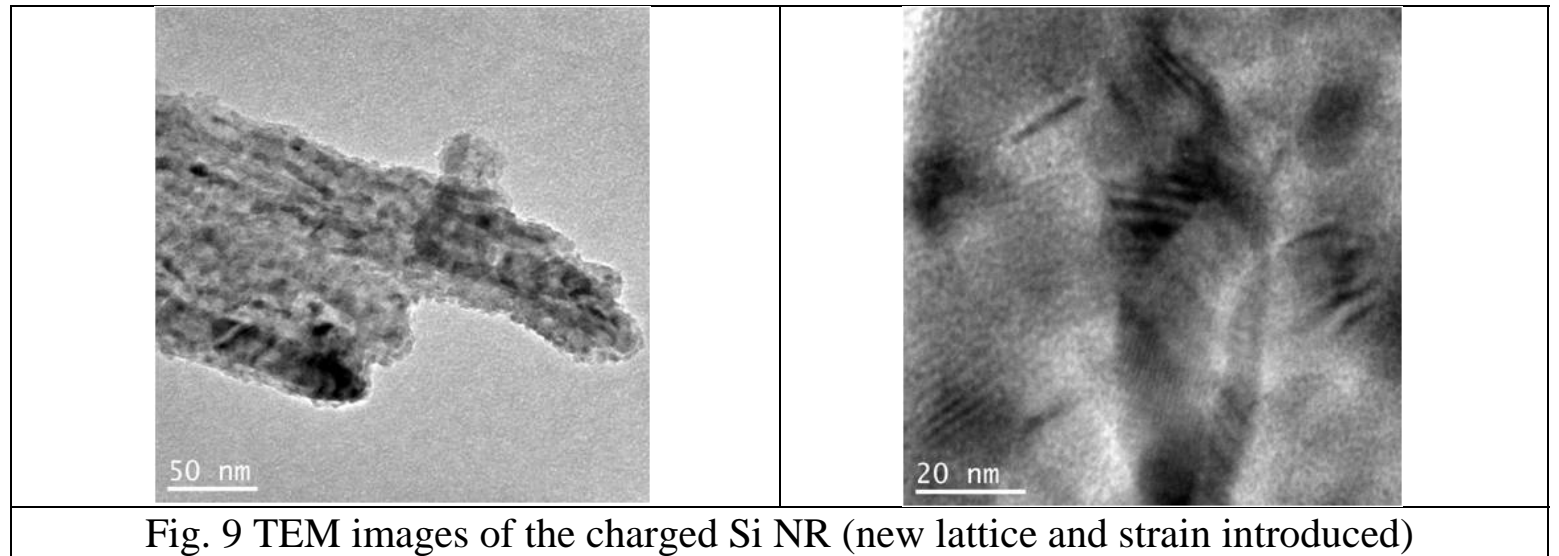



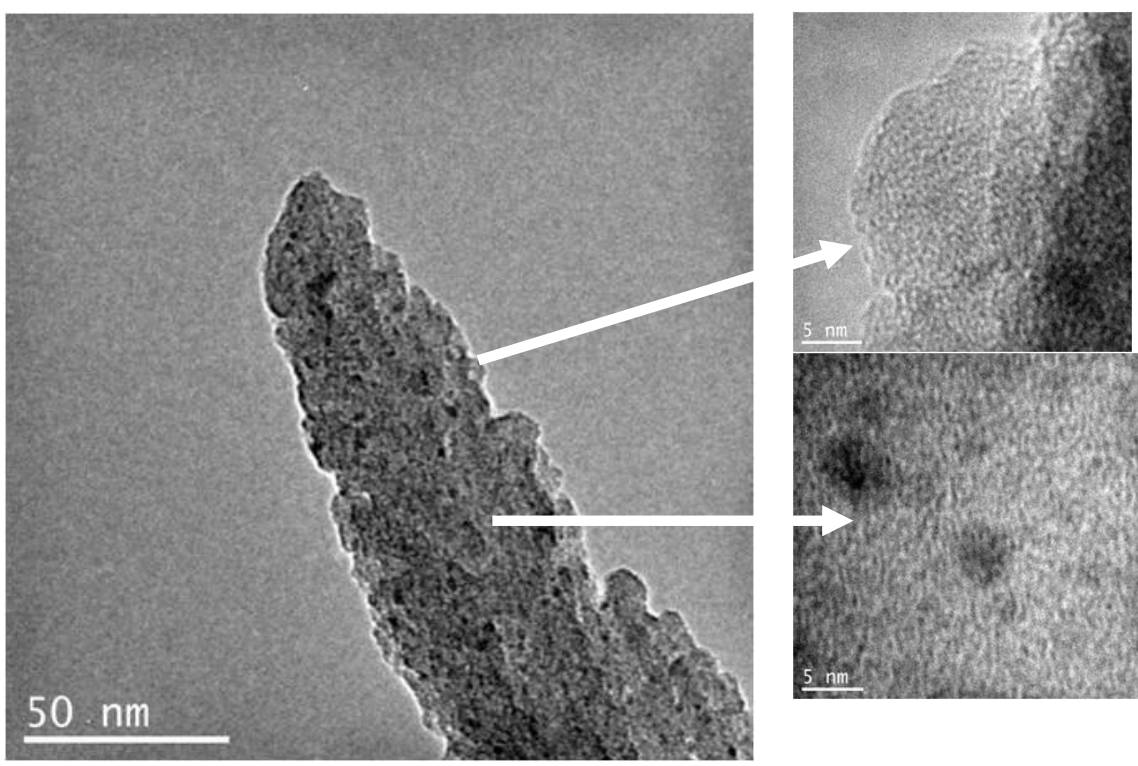

Fig. 10 TEM images of the discharged Si NR. (in amorphous state)

The Li-SiCu NR cell performs differently. It demonstrated $3500 \mathrm{mAh} / \mathrm{g}$ capacity in the first charge. The capacity decreased to $800 \mathrm{mAh} / \mathrm{g}$ in the second cycle, but sustainable in following 100 cycles (Fig.11). SEM observation shows that the surface of SiCu NR become rough, but remain in aligned orientation after full charged. Due to its flexibility and less brittle nature (see Fig.4), the SiCu NR were able to maintain their integrity and survived for 100 cycles. The TEM shows the virgin SiCu NR have the amorphous and crystalline mixing structure. The crystalline regions correspond to SI-Cu compounds such as $\mathrm{Cu}_{3} \mathrm{Si}$ and $\mathrm{Cu}_{5} \mathrm{Si}$ (Fig.14). Similar as the Si NR, the lithiation of SiCu NR produces LiSi alloys and introduces strain causing surface roughness (Fig.15). After discharge, the surface of $\mathrm{SiCu}$ NR returns to smooth, but the crystalline grains and strain remained. The local stress does not seem relax completely (Fig.16). It implies that the changes of the morphology and structure of $\mathrm{Si}$ and $\mathrm{SiCu} \mathrm{NR}$ are not completely reversible. It proved that the large capacity lose in the first cycle is not recoverable. But, the cyclable capacity can be sustained by tuning of the structure and composition of the nanostructured Si anodes.

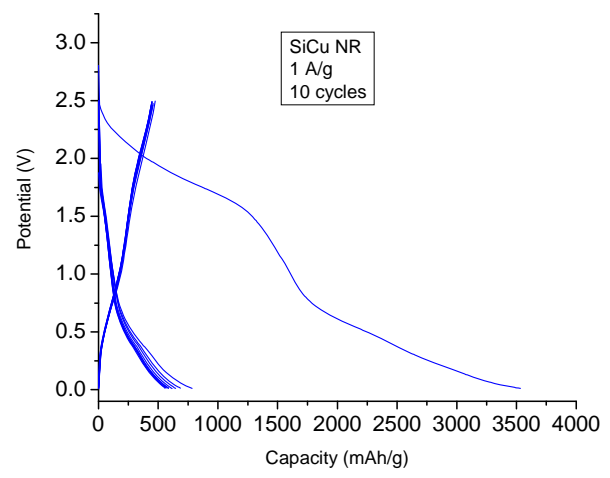

Fig. 11 The first 10 cycles of Li-SiCu NR cell

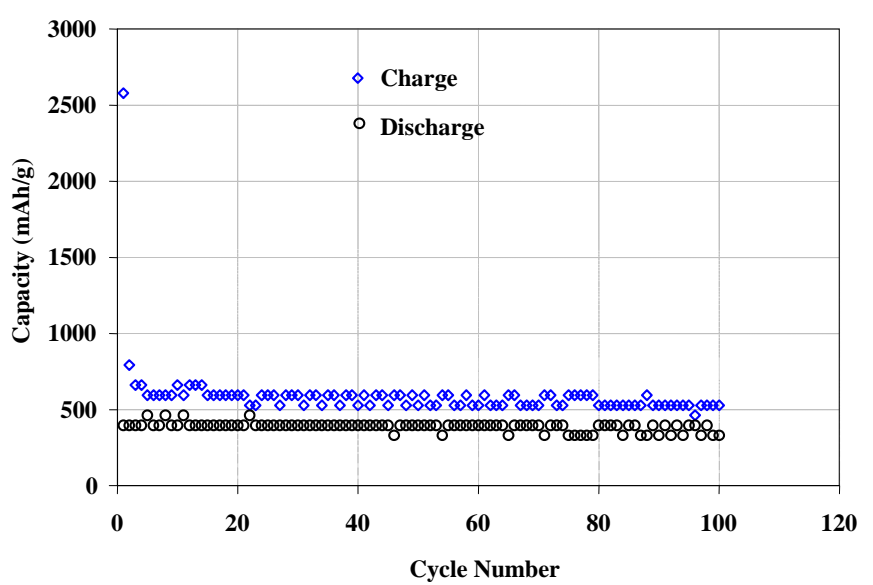

Fig.12 The 100 cycles of Li-SiCu NR cel 


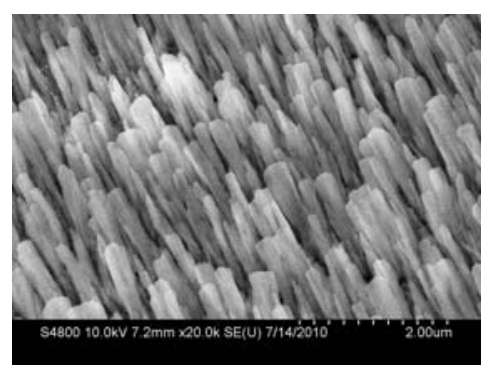

Fig.13 (a) The virgin SiCu NR

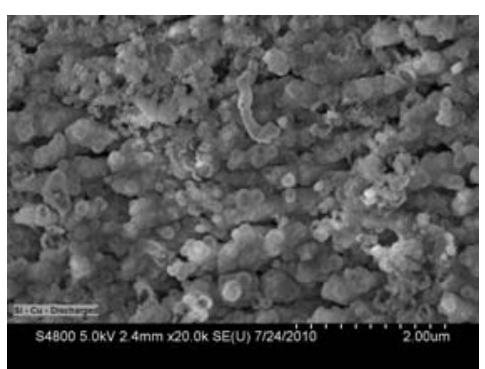

Fig.13(b) The full charged $\mathrm{SiCu}$ NR

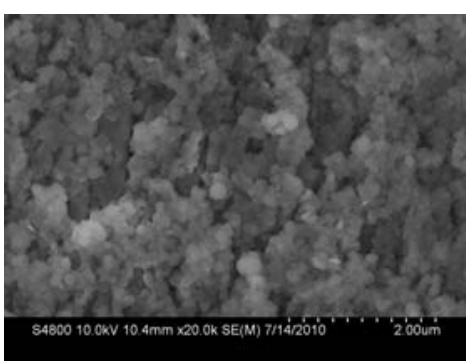

Fig.13 (C) The SiCu NR after 100 cycles at full charged state

Fig.13 The morphology changes of SiCu NR
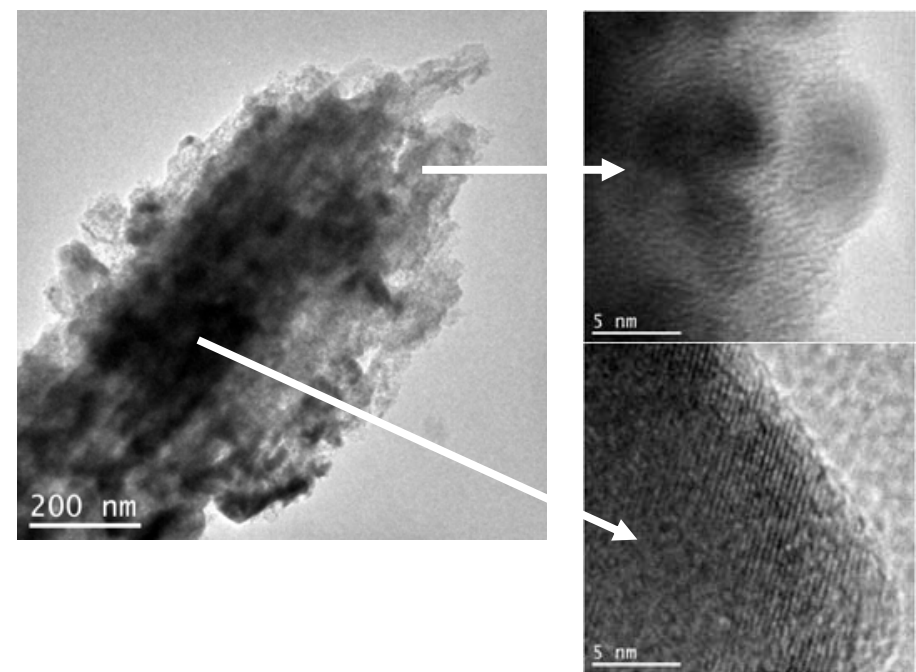

Fig.14 TEM image of the virgin SiCu NR shows the amorphous structure with scattering crystalline regions corresponding to $\mathrm{Si}-\mathrm{Cu}$ compounds.
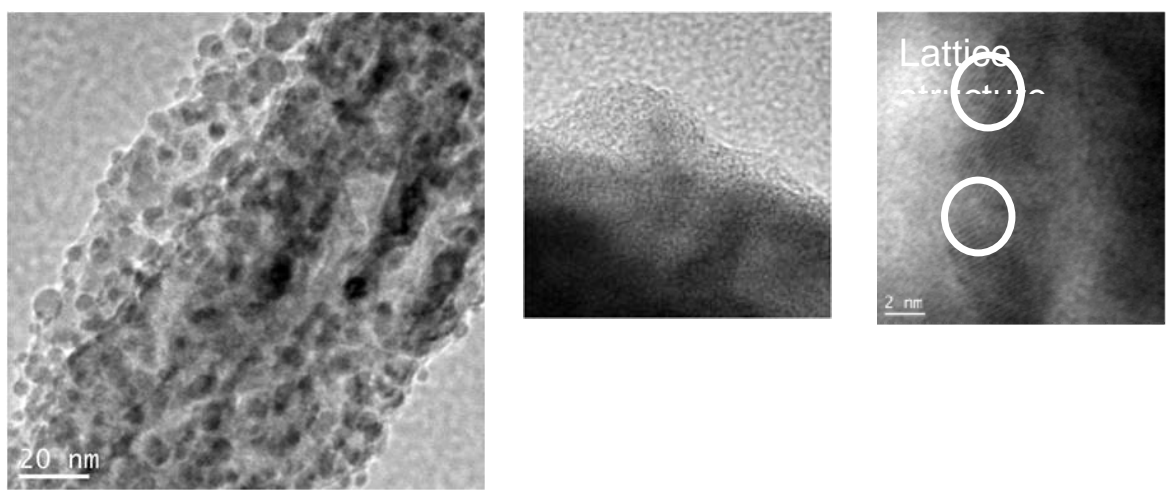

Fig.14 TEM images of the charged SiCu NR shows the rough surface and amorphouscrystalline mixed structure. The crystalline regions correspond to the $\mathrm{Si}-\mathrm{Cu}$ compounds 

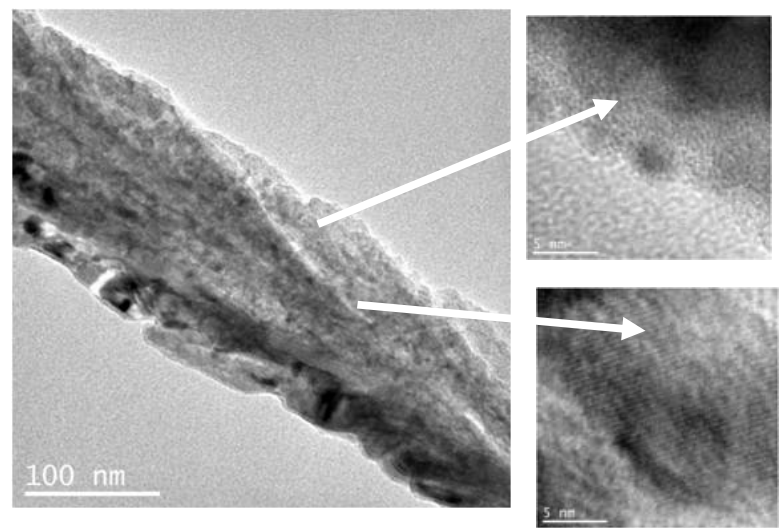

Fig.15 TEM images of the discharged SiCu NR shows the smooth surface, amorphous and crystalline regions that may associate with Li-Si compounds remained in the anode

\section{Conclusions}

The aligned Si nanorods show anodic capacity of $1500 \mathrm{mAh} / \mathrm{g}$ in the first charge. Unfortunately, the high initial capacity was decreased rapidly and diminished after 50 discharge-charge cycles that attributes to the morphology change and pulverization due to brittle nature of silicon. Si-Cu composite nanorods demonstrated $3500 \mathrm{mAh} / \mathrm{g}$ capacity in the first charge. Although the capacity was decreased to $800 \mathrm{mAh} / \mathrm{g}$ in the second cycle,

but it is sustainable for 100 cycles. SEM,TEM observation and AFM measurement indicated that adding $\mathrm{Cu}$ into the $\mathrm{Si}$ nanorods provides the flexibility and reduces the brittleness of silicon that makes the structure more stable. The morphology change of Si and $\mathrm{SiCu}$ nanorods during electrochemical charge and discharge are not complete reversible that may contribute to low columbic effect and unrecoverable capacity lose in the first cycle. Tuning the composition and the structure of nanostructured Si will lead to practical approach to leverage the advantage of Si based anode materials in Li-ion battery application.

\section{Acknowledgement}

This work is financially supported by Savannah River National Laboratory LDRD Program. Savannah River National Laboratory is operated by Savannah River Nuclear Solution for US Department of Energy under contract DE-AC09-08SR22470.

\section{References}

[1] Ming Au et al, Journal of Power Source, 195(2010)3333-3337

[2] I. Sandu et al, Sol.Sta.Ion. 178(2007)1297-1303

[3] N.Dimov et al, J.Power.Sources. 171(2007)886-893

[4] E. Hosono et al, J.Ele.Chem. 154,2 (2007)A146-A149 
[5] K.Ui et al, J.Power.Sources. 189(2009)224-229

[6] X.Let et al, J.Alloy.Comd. 429(2007)311-315

[7] C.C.Chang et al, J.Phys.Chem.C. 2007, 111, 16423-16427

[8] N.Li et al, J.Power.Sources. 97-98(2001)240-243

[9] Y-M.Kang et al, J.Power.Sources. 133(2004)252-259

[10]S-H.Lee et al, Adv.Mat. 2006,18,763-766

[11] Ming Au et al, Journal of Materials Research, Focus Issue on Materials for Electric Energy Storage, V25,N8, (2010)1549-1655

[11] Y-P. Zhao et al, Proc.SPIE. Nanotubes\&Nanowires, Ed.A.Lakhtakia, Bellingham, WA, 2003

[12] "Smithells Metals Reference Book", Edited by E.A.Brades and G.B.Brook, $7^{\text {th }}$ Edition, Publisher: Butterworth-Heinemann in1998. 